\title{
LA SOBERANÍA DEL ESTADO EN SU CONTEXTO HISTÓRICO. NOTAS SOBRE HOBBES, LOCKE Y ROUSSEAU
}

\author{
Ana Maria Jara \\ Gómez ${ }^{1}$
}

\section{Resumen}

Resulta fundamental la idea de que existe una necesidad de contextualización histórica de los conceptos jurídico-políticos, que, por mucho que cambien y se modulen en el tiempo, siempre son, en mayor o menor medida, deudores del momento histórico de su génesis. Este estudio pretende poner de relieve algunos de los antecedentes históricos más importantes a la hora de realizar una aproximación al concepto de soberanía. La soberanía tiene un pasado, una tradición, y el conocimiento de este pasado permite contemplar nuevas limitaciones, correcciones e interpretaciones en su análisis jurídico. Lo que se tratará de hacer, en esta breve historia del concepto de la soberanía, es profundizar en lo que significa su adopción como presupuesto fundamental de la existencia del Estado, y no tanto del gobierno. Su importancia radica en que detrás de los principios y los paradigmas de la soberanía, existe una realidad de tensiones que afectan los procesos jurídico-políticos, cuyo origen es imprescindible comprender.

Palabras Clave: Soberanía, Estado moderno, Hobbes, Locke, Rousseau.

\section{INTRODUCCIÓN}

Numerosos estudios abordan en las últimas décadas el problema de la crisis o la transformación del viejo concepto de la soberanía estatal, una cuestión sin duda compleja, que resulta intrincada de resolver, vista la acelerada y convulsa evolución del Estado contemporáneo.

Siguiendo a David Kennedy "la soberanía trata de cómo somos gobernados. De dónde está el poder: quién está arriba y quién está abajo; quién está dentro, quién está fuera; quién puede decidir; sobre qué pueden decidir; cuánta capacidad pública está

\footnotetext{
${ }^{1}$ Doctora en Derecho por la Universidad de Granada, investigadora permanente del Grupo de Investigación “Derechos Fundamentales, Andalucía y CE” de la Universidad de Jaén (España), Magistra (LLMeur) en Derecho Europeo e Internacional por la Universidad de Bremen (Alemania). Email: anajaragomez@gmail.com
} 
disponible; y quién puede impugnar esto" ${ }^{2}$. La soberanía se presenta, por lo tanto y desde un principio, como un concepto distributivo y atributivo del poder, que tiene una función tanto dogmático-jurídica, como teórico-jurídica y teórico-constitucional. Al mismo tiempo, la soberanía, debido al elemento de poder que le es inherente, remite a un contexto político más amplio, por encima del derecho, sin el que no es posible desarrollarla. Se le puede, por tanto, atribuir tanto una función descriptiva como una función prescriptiva, según se elija un punto de partida fáctico, de su existencia como último poder de decisión, o bien uno normativo, que constata que ninguna comunidad estatal jurídicamente organizada puede existir sin ella ${ }^{3}$.

En todo caso, es incuestionable que el concepto de soberanía provoca, por sí solo, grandes desacuerdos y controversias interminables, precisamente porque el tema de la soberanía resulta prioritario para la comprensión de la vida política global. Sin embargo, como institución en permanente proceso evolutivo y dependiente de la acción de grandes poderes, incontrolados y no siempre visibles, y potencias, visibles y no siempre controlables, el centro del debate reside en el locus de la soberanía real, entendiendo por ello quién gestiona/administra real y efectivamente el Estado y cuál es el resultado de esa gestión.

Sin embargo, no se trata aquí de analizar o cuestionar el nuevo equilibrio de poderes entre Estados y un conjunto heteróclito de actores constituido por las Organizaciones no Gubernamentales, las Organizaciones Internacionales, las empresas multinacionales, los operadores financieros, los terroristas, las mafias y una infinidad de otros actores privados. No hemos de profundizar en la soberanía del Estado en la escena mundial o su decadencia, aunque conviene recordar que:

El Estado no solo es una de las normas mejor implantadas del sistema internacional, sino que además es una de las formas de organización política más solicitada. Las rebeliones, los movimientos separatistas o autonómicos que recurren a la violencia no atacan al Estado en su esencia; apuntan más bien a la reconstitución, en todo el territorio nacional o en parte de él, de un Estado bajo su control. No son hostiles al Estado como tal. Al contrario. Nadie tiene "deseo de Estado" tanto como ellos, a

\footnotetext{
${ }^{2}$ KENNEDY, David, "Sovereignty: Responding to Anghie and Aravamudan", Texas International Law Journal, vol. 3, verano 2006, p. 465.

3 WYDUCKEL, Dieter, La Soberanía en la Historia de la Dogmática Alemana, disponible en http://www.unioviedo.es/constitucional/fundamentos/primero/pdf/wyducke.pdf.
} 
condición de que sea el "suyo", puesto bajo su control, dotado de atributos "normales" de la soberanía y que se beneficie de fronteras "seguras y reconocidas". Los palestinos no luchan contra el Estado sino contra Israel. El Partido de los Trabajadores de Kurdistán (PKK) no quiere la desaparición de Turquía sino la constitución de un Kurdistán autónomo. Los Tigres tamules se sublevaron contra el gobierno cingalés, pero no contra el Estadonación. Este sigue siendo una forma de organización muy apreciada por aquellos mismos que lo combaten. Prueba de ello es la 'proliferación de Estados' que el mundo ha visto desde la descolonización, el hundimiento de la URSS y de Yugoslavia. Toda desaparición de un Estado se traduce en su fragmentación y en la creación de varias entidades distintas, que afirman su soberanía y reivindican fronteras y un territorio"4.

Esto significa que, a pesar de existir numerosas opiniones que hablan de la soberanía como un dogma anticuado, apelando a la falta de autonomía del Estado moderno, a las obligaciones de cooperar institucionalmente tanto con socios no estatales como en sus relaciones internacionales con otros Estados, este modelo permanece como el más demandado.

A pesar de todo, pareciera que el Estado, por hallarse limitado en la toma de decisiones y en su capacidad de regulación, por las dificultades que encuentra para imponer sus intereses, ya no pueda ser considerado soberano. Sin embargo, "esa visión precipitada opera con un concepto sociológico de soberanía, aquel que equipara la soberanía a un uso ilimitado del poder estatal y que al partir de dicha premisa, en vistas de la falta de omnipotencia del Estado, se ve obligada a negarle su soberanía"5.

Este panorama supone una nueva forma de vida política multidimensional, centrada en la administración de lo económico y lo social, un sistema cuya naturaleza heterodoxa desborda el marco jurídico legal en el que habitualmente se dilucidan cuestiones relativas a la soberanía. Por razones obvias no podemos embarcarnos en los juicios de validez de las distintas visiones conceptuales y su significado, pretendemos aquí, modestamente, exponer varios de los razonamientos de los teóricos de la soberanía que pueden arrojar luz sobre algunas de las diversas formas de entenderla que se han dado en la historia.

${ }^{44}$ COHEN, Sami, "Les États et les "nouveaux acteurs"', Politique internationale, $\mathrm{n}^{\circ}$ 107, primavera 2005, p. 1.

${ }^{5}$ HILLGRUBER, Christian, "Soberanía-La Defensa de un Concepto Jurídico", InDret Revista para el Análisis del Derecho, Barcelona, vol. 1, 2009, p. 4. 
Es obligado, sin embargo, detenerse en estos aspectos porque sólo una vez caracterizada la soberanía y vistas sus principales tesis o propuestas teóricas, se puede abordar o profundizar en los postulados de la gobernanza, los derechos y sus garantías o el nacimiento del Estado. La soberanía tiene un pasado, una tradición, y el conocimiento de este pasado permite contemplar nuevas limitaciones, correcciones e interpretaciones en su análisis jurídico.

Lo que se tratará de hacer, en esta breve historia del concepto de la soberanía, es profundizar en lo que significa su adopción como presupuesto fundamental de la existencia del Estado, y no tanto, del gobierno. Porque, detrás de los principios y los paradigmas de la soberanía, existe una realidad de tensiones que afectan los procesos jurídico-políticos, cuyo origen es imprescindible comprender ${ }^{6}$.

Los clásicos de la modernidad transformaron la triada teórica medieval de derecho natural, divino y territorial en un nuevo orden político concreto usando la noción de soberanía como envoltorio de todo poder. Hoy vivimos una situación comparable a la hora de explicar la funcionalidad de muy diversos poderes en la práctica política así como la funcionalidad de entidades supranacionales en una era de conflictos con los intereses nacionales. Parece necesario un intento de buscar soluciones utilizando de nuevo la construcción de la soberanía como significante más que como norma jurídica o institución legal. Tal vez, como afirman algunos autores, no es el concepto en general sino sus usos específicos los que productivamente han de ser discutidos y elaborados ${ }^{7}$.

El derecho global de hoy es anti-formalista y se nos dice que "lo que cuenta es la existencia de un poder de facto, cualquiera que sea su origen y objetivos. Sólo ese poder

\footnotetext{
${ }^{6}$ No conviene perder de vista el carácter histórico del concepto, en el sentido y con el alcance con que delimitó los términos el profesor González Vicén en referencia a la definición de Filosofía del Derecho. Los conceptos son históricos por "su vinculación esencial a una estructura histórica... sistematización y ordenación desde un punto de vista relevante de tendencias, tensiones, corrientes ideológicas, relaciones de sentido, valoraciones; en suma, de todo un mundo de significaciones que se da como singularidad concreta en un momento determinado del tiempo histórico". Precisamente, el carácter "soberano" del poder tipifica y concreta el concepto de Estado, el ejemplo más expresivo de concepto histórico, en opinión del propio González Vicén. GONZÁLEZ VICÉN, Felipe, Estudios de Filosofía del Derecho, Universidad de La Laguna, 1979, pp. 207-208 y 240. Para una mayor comprensión no puede prescindirse de la consulta a la obra de Juan Antonio Carrillo Salcedo, Soberanía del Estado y Derecho Internacional, Tecnos, Madrid, 1976.

${ }^{7}$ SENN, Marcel, "Sovereignty - Some critical Remarks on the Genealogy of Governance", Journal on European History of Law, vol. 1, № 2, 2010, p. 11.
} 
alcanzará el bien común para todos"․ Esta aseveración no es una extravagancia postmoderna, la soberanía no apareció como invención filosófica sino que fue producto del cansancio de Europa por los conflictos religiosos y su propósito era práctico: acabar con el poder papal e imperial y pacificar las sociedades europeas. La clave estaba precisamente en apartarse de lo trascendental y acercarse al poder del productor de normas secular que requiere estar controlado para lograr el beneficio de la población. Sin poder, ni la seguridad ni el bienestar pueden existir y el vínculo entre protección y obediencia queda roto, permitiendo que emerja la 'anarquía's.

\section{IUSNATURALISMO RACIONALISTA Y ESTADO MODERNO, LAS DOS CARAS DE UNA MISMA MONEDA}

Las vicisitudes históricas del Estado moderno, ha escrito Giacomo Marramao, están ligadas a las definiciones de la soberanía dadas en los siglos XVI, XVII y XVIII, por Bodin, Hobbes y Rousseau, respectivamente ${ }^{10}$. No obstante, esta indudable centralidad del concepto de soberanía no nos debería impedir el reconocimiento, suscrito por el propio filósofo italiano, de que su evolución histórica lo ha ido transformando hasta convertirlo desde "gran encrucijada" a "tierra de paso".

No existe unanimidad en la doctrina para datar exactamente el momento del surgimiento del Estado Moderno, y, por consiguiente, del concepto moderno de soberanía estatal. En este sentido, existen no pocos autores que afirman que ya existían, no solo las características propias de la soberanía, sino también Estados modernos, en algunos reinos avanzados del siglo XIV. Parte de la doctrina sostiene, en definitiva, que se dieron antes los hechos que los conceptos ${ }^{11}$.

Los comienzos de la teoría de la soberanía pueden encontrarse tempranamente en La Política de Aristóteles y en el Derecho Romano clásico. En La Política se reconoce

\footnotetext{
${ }^{8}$ KOSKENNIEMI, Martti, “What Use for Sovereignty Today?", Asian Journal of International Law, vol. 1, 2011, p. 68.

9 Véase KOSKENNIEMI, Martti, From Apology to Utopia. The Structure of International Legal Argument, Cambridge University Press, 2005, p. 17. Véase también FERRAJOLI, Luigi, "La crisis de la democracia en la Era de la Globalización”, Anales de la Cátedra Francisco Suárez, IVR 2005, pp. 37-51.

${ }^{10}$ MARRAMAO, Giacomo, "Soberanía: para una Historia Crítica del Concepto", Anales de la Cátedra Francisco Suárez, no 29, 1989, pp. 35 y ss.

${ }^{"}$ GARCÍA GESTOSO, Noemí, "Sobre los Orígenes Históricos y Teóricos del Concepto de Soberanía: Especial Referencia a los Seis Libros de la República de J. Bodino", Revista de Estudios Políticos, no 120, abril-junio 2003, p. 302.
} 
el hecho de que debe existir un poder supremo y que este poder puede estar en manos de uno, de unos cuantos o de muchos. En el Capítulo VI del Libro Tercero aparece la justificación a la regla de la mayoría: "Atribuir la soberanía a la multitud antes que a los hombres distinguidos, que están siempre en minoría, puede parecer una solución equitativa y verdadera de la cuestión, aunque aún no resuelva todas las dificultades". En la época romana, la idea de la soberanía encontró su expresión más clara en la conocida frase "la voluntad del príncipe tiene fuerza de ley puesto que el pueblo le ha transferido todo su derecho y su poder" ${ }^{\prime \prime 2}$.

Fue el interés renovado en el Derecho Romano durante el s. XII y el estudio de las redescubiertas obras de Aristóteles en el XIII el germen de las proposiciones fundamentales presentes en las teorías que sobre la soberanía habían de surgir a causa de las luchas entre la iglesia y el Estado ${ }^{13}$. El mismo Tomás de Aquino, tratando de conciliar el sistema aristotélico con la teología cristiana, enseñaba que el supremo poder provenía de fuentes puramente humanas, es decir, de los actos del pueblo. La autoridad del Papa, sostenía, le era dada directamente por Dios mientras que la del emperador procedía del consentimiento del pueblo y la cooperación de la Iglesia. De este modo, puede afirmarse que la idea de la soberanía popular está presente antes de la sistematización de la teoría del Estado moderno, y que un axioma de la teoría política desde el final del s. XIII fue que todo gobierno tiene su justificación en la sumisión voluntaria de la comunidad gobernada ${ }^{14}$.

La concreción del Cristianismo en un poder, la Iglesia, dirigida por el Papa, dio lugar a enfrentamientos con las dinastías germánicas que reclaman la sucesión del Imperio romano. Y es que ambos poderes, Iglesia e Imperio, "manifiestan las mismas pretensiones de dominio sobre una comunidad universal y, por tanto, de exclusividad"15. El Cristianismo rompe la antigua unidad de la comunidad política y hace surgir, junto a la ley humana, otra ley, la eterna y natural. A esta ley divina han de quedar subordinados los órdenes temporales de poder, en el sentido de la máxima pauliana «no

\footnotetext{
${ }^{12}$ La cita corresponde a las Institutiones de Justiniano, que expresa: "Sed et quod principi placuit, legis habet vigorem, cum lege regia, quae de imperio eius lata est, populus ei et in eum omne suum imperium et potestatem concessit".

${ }^{13}$ MERRIAM JR., Charles Edward, History of the Theory of Sovereignty since Rousseau, Batoche Books, Kitchener, 2001, p. 6.

${ }^{14}$ Ibídem.

${ }^{15}$ GARCÍA GESTOSO, Noemí, Sobre los Orígenes Históricos..., op. cit., supra. 8, p. 303. 
hay poder sino de Dios». De este modo, la Iglesia reclamaba su papel legitimador de las estructuras de poder ${ }^{16}$.

La deslegitimación de la teología como base del viejo "derecho natural", sustanciada bajo el signo de la secularización, convertirá al iusnaturalismo moderno en una poderosa herramienta para dominar y conformar la realidad social, jurídica y política, desde una metodología importada de las ciencias naturales y cercana, por tanto, al empirismo. Un racionalismo disociado de la teología y un individualismo liberado de la tutela de la religión van a posibilitar, en última instancia, la transformación y el desplazamiento de los viejos centros de poder sobre los que se asentaban las monarquías medievales hasta un nuevo modelo de Estado. El derecho natural, tal como lo concibe el hombre moderno, es un conjunto de principios que emanaban de la razón y servían a la razón como despliegue de la libertad ${ }^{17}$. Como ha señalado Elías Díaz:

Precisamente la ruptura del monolitismo y la uniformidad religiosa por obra de la Reforma protestante, iba a llevar coherentemente a la necesidad histórica de un iusnaturalismo no fundado de modo ineludible en la ley eterna... Si se quiere encontrar un concepto unitario de Derecho natural, aceptado por todos los hombres, sean cuales fueren sus ideas religiosas, se hace preciso independizar aquél de éstas. En el nuevo clima de incipiente racionalismo (siglos XVI y XVII) de afirmación de la autonomía e independencia de la razón humana frente a la razón teológica, se piensa que la base y el fundamento de ese Derecho Natural no puede ser ya, decimos, la ley eterna, sino la misma naturaleza racional del hombre, que corresponde y pertenece por igual a todo el género humano: la razón, se dice, es lo común a todo hombre. Sobre ella se puede construir un auténtico y nuevo Derecho Natural"18.

El derecho natural racional opera en el plano de la teoría en virtud de la cual los derechos individuales limitan el poder del Estado, pero únicamente adquieren su plena vigencia en el Estado, que requiere de la coacción para que el derecho posibilite la coexistencia de las libertades individuales ${ }^{19}$. Dios se va así desvaneciendo del horizonte

\footnotetext{
${ }^{16}$ Ibid., p. 304.

${ }^{17}$ GÓMEZ ARBOLEYA, Enrique, Historia de la Estructura y el Pensamiento Social, Instituto de Estudios Políticos y Constitucionales, Madrid, 1976, p. 139.

${ }^{18}$ DÍAZ, Elías, Sociología Filosofía del Derecho, Ed. Taurus, Madrid 1980, pp. 270-271.

${ }^{19}$ Véase, entre otros, GINER SANJULIÁN, Salvador, Historia del Pensamiento Social, (12ª ed.), Ariel, 2008, p. 207 y ss.
} 
intelectual europeo, hasta el punto de que en las relaciones internacionales no podrá distinguirse ya entre naciones cristianas e infieles. La aparición de la fuerza y la coacción como elementos esenciales del derecho y la desaparición progresiva de Dios incrementarán la consideración filosófica del Estado como poder absoluto. El Estado se convierte en un hecho perfectamente claro y comprensible cuando se le atribuye un origen de esa índole, figura central del iusnaturalismo moderno. Los agentes del contrato son individuos en el estado de naturaleza y su resultado es un cuerpo social y político construido artificialmente en beneficio de los que lo suscriben ${ }^{20}$.

Aunque existieran divergencias entre los autores del s. XVII en cuanto a los principios del orden social y político, hay acuerdo en el empleo del contrato social, y en que este orden se reduce a una sumisión voluntaria de los gobernados ${ }^{21}$. El individualismo es común al mito del estado de naturaleza, dotando al iusnaturalismo de un carácter progresista, frente al orden feudal, y también clasista. Se abandona al individuo a las fuerzas del mercado en una sociedad que favorece las relaciones de explotación y dominación, originándose situaciones de exclusión y de abandono social para las que el iusnaturalismo moderno y su derecho no habían previsto solución.

Con el nacimiento del mundo moderno el espacio de la política es conceptualizado y encarado, ante todo, como una construcción humana, nacida de la racionalidad humana y apta para unas relaciones sociales que han de desplegarse en el ámbito de lo humano, con su propia ratio, distinta de la ratio theologica. Por eso cambia incluso su denominación, apareciendo en Maquiavelo la designación de lo stato, que describía hasta entonces la situación cambiante e instantánea de una persona o entidad. Lo stato sustituye a la clásica res publica y este cambio en los términos subraya una realidad nueva: la vida política se hace móvil, ahora es un mundo cambiante creado por humanos. Es el momento heroico del Estado naciente, y su creación lleva adherida

\footnotetext{
${ }^{20}$ Véase SAAVEDRA LÓPEZ, Modesto, Doce Lecciones de Filosofía del Derecho, Universidad de Granada, 2011, p. 62.

${ }^{21}$ "Una de las categorías fundamentales de la realidad social-histórica es el consensus, esto es, un complejo que liga profunda y unitariamente las distintas manifestaciones de la vida y las hace solidarias. Todo intento de aislamiento artificial fracasa. Fracasa porque es infiel a la parte que resulta. Esta sólo vale en conexión con el conjunto. El único procedimiento válido es un método dialéctico que recoja en su implicación los distintos sectores o, por lo menos, que al destacar uno tenga en cuenta la resonancia del todo en él y de él en el todo", GÓMEZ ARBOLEYA, Enrique, Historia de la Estructura..., op. cit., supra 16, p. 109.
} 
la noción de "razón de Estado": el cálculo de medios y fines ${ }^{22}$. El Estado, provisto de reglas y racionalidad propias, condiciona el proceder de los propios "hombres de Estado" sin limitación de medios, sin más condicionalidad ni sometimiento a plan distinto al puro mantenimiento del poder. "Procure, pues, el príncipe conservar su Estado, -advertirá Maquiavelo- y los medios serán siempre tachados de honrosos y ensalzados por todos porque el vulgo se deja seducir por las apariencias y el acierto final y en el mundo no hay sino vulgo"23.

No deja de constituir una llamativa ironía histórica el hecho de que la nueva idea del poder absoluto del soberano en el Estado naciese vinculada a la violencia y la guerra civil. Como acertadamente escribiera Schulze, "a grandes rasgos es válido decir para Europa que a partir de las relaciones feudales de la Edad Media y del Renacimiento se formó el Estado principalmente secular, liberado de la tutela eclesiástica y, a la vez, autoritario y soberano. La lucha por el poder en el Estado y con ella la cuestión de la soberanía se decidieron en las guerras civiles y de religión de los siglos XVI y XVII: el Estado y el soberano coincidían -al menos idealmente- en uno"24.

En Francia, Jean Bodin argumentaba de modo histórico: la posición del soberano reposa sobre el antiguo derecho del reino. Esta no resultaba una argumentación convincente para su tiempo. Fascinado por la lógica, se reclamaba la justificación de un derecho sobre el que fundar la constitución y existencia del poder soberano. Una explicación de tal índole existía ya, pero era argüida por los enemigos del poder absoluto del príncipe: se trataba de la doctrina del pacto de soberanía establecido entre el pueblo y el señor, en el que por regla general aparecía como garante del pacto un tercer poder, la Iglesia. La idea del pacto de soberanía se postula, entre los enemigos del absolutismo, para fundamentar por qué estaba justificado el derecho a la resistencia activa contra los señores tiránicos que hubiesen roto el pacto ${ }^{25}$.

Sea como fuere, el poder político como instancia suprema lleva a la afirmación de la soberanía, un concepto que encierra la totalidad de la vida política y jurídica. Bodin modela la noción perdurable del poder político como poder supremo, distinto de cualquier otro, creador del derecho. Bodin, en su definición de la soberanía, utiliza el

\footnotetext{
${ }^{22}$ GÓMEZ ARBOLEYA, Enrique, Historia de la Estructura..., op. cit., supra 16, p. 135.

${ }^{23}$ MAQUIAVELO, Nicolás, El Príncipe, M. E. Editores, Madrid, 1995, p. 123.

${ }^{24}$ SCHULZE, Hagen, Estado y Nación en Europa, Grijalbo-Mondadori, Barcelona, 1996, p. 64.

${ }^{25}$ Ibid., pp. 51-52.
} 
término absoluta, heredado de la experiencia del derecho romano donde estaba conectada con las prerrogativas soberanas (legibus solutus). Para Bodin, el Estado no se puede apoyar en una creencia teológica, tampoco en el determinismo geográfico; la forma que constituye una comunidad en república es la soberanía, entendida como potestad absoluta y perpetua, siendo el elemento esencial de tal potestad la facultad de dar leyes, atributo que distingue a quien manda de aquéllos que han de obedecer. La soberanía es una potestad absoluta, dado que "si la Corona se quiebra, no es corona" y debe tener un único titular, viniendo sus limitaciones exclusivamente del orden moral del mundo ${ }^{26}$.

En las teorías de Bodin el despotismo puede llegar a ser apropiado, incluso legal, pero la tiranía jamás puede gozar de legitimidad, puesto que es contraria a la ley divina y natural. El soberano de Bodin no puede estar sujeto a la ley positiva, sino exclusivamente al derecho divino y al derecho natural ${ }^{27}$. Las diferencia que realiza Bodin entre despotismo y tiranía parecen minimizar la salida del derecho divino y natural como fuentes de la autoridad soberana, restando claridad al hecho de que el soberano reciba su autoridad de un cuerpo político.

En efecto, pese a tratarse de un legislador confesionalmente neutral, el soberano de Bodin mantiene su objetivo de lograr un gobierno justo, respetuoso con el orden divino y la ley natural. Mediante la limitación del carácter absoluto de la soberanía Bodin nos descubre, indiciaria e indirectamente, otro importante ángulo del poder del Estado: el poder como protector y garante de los derechos individuales. Bodin contradice, ciertamente, a Maquiavelo, pero a pesar de todo no logra fundamentar la legitimidad del poder único, indivisible e ilimitado temporalmente, que caracteriza la soberanía, tampoco llegará a tematizar aquel que será elemento central en el itinerario de su legitimación: la idea del pacto de soberanía ${ }^{28}$.

\footnotetext{
${ }^{26}$ Véase BODIN, Jean, Los Seis Libros de la República, Tecnos, (4⿳⺈冂䒑 ed.), Madrid, 2006. Y, entre otros, MESNARD, Pierre, Jean Bodin en la Historia del Pensamiento, Instituto de Estudios Políticos, 1962; MESNARD, Pierre, Oeuvres philosophiques de Jean Bodin, Presses Universitaires de France, París, 1951; y BLAIR, Ann, The theater of nature: Jean Bodin and Renaissance science, Princeton University Press, 1997.

${ }^{27}$ NAGAN, Winston P. y HADDAD, Aitza M., "Sovereignty in Theory and Practice", San Diego International Law Journal, vol. 13, 2012, p. 441.

${ }^{28}$ Ibid., p. 50 y ss.
} 
THOMAS HOBBES: LA SOBERANÍA ABSOLUTA, INDIVISIBLE E IRREVOCABLE

Será Thomas Hobbes quien aporte las claves para enmarcar dicho poder. A partir de la concepción del contrato social, tomado como fundamento, Hobbes establecerá los cimientos del absolutismo. Los seres humanos, en su estado de naturaleza, viven en una lucha permanente y continua. Los individuos, para Hobbes, con el objetivo de conseguir la paz y la preservación de sí mismos, han creado un hombre artificial llamado Estado (suma de todos los poderes individuales) y han creado también las leyes que han sido establecidas por pactos entre ellos.

Sin embargo, si bien en la filosofía hobbesiana está presente el elemento del contrato, el autor inglés concibe a la soberanía del Estado como una unidad indivisible y absoluta. Es posible que Hobbes tuviera presentes las luchas religiosas que habían provocado las guerras civiles en la Inglaterra de su tiempo. Sostiene, por tanto, firmemente la idea de la superioridad y supremacía del poder del Estado, al cual deben subordinarse todos los demás grupos políticos y sociales. Este carácter absoluto de la soberanía se apoya en que el Estado representa como un todo a las voluntades de aquéllos que prestaron consentimiento a su constitución. Al respecto, Hobbes aclara que esa persona artificial constituye una unidad en sí misma, y, una vez concedida la autoridad, queda implícito el consentimiento de la multitud, que se ha vuelto una unidad en virtud de la representación ${ }^{29}$.

Para Bobbio, la figura del contrato de Hobbes no se corresponde con el pactum societatis, que conduce a una sociedad de ayuda mutua entre los individuos, ni tampoco con el pactum subiectionis, que se efectúa entre el pueblo y el soberano y que implica el cumplimiento de obligaciones por parte del soberano y la recuperación de la soberanía para el pueblo en caso de inobservancia de dichas obligaciones. El contrato hobbesiano es un pacto entre individuos singulares que coinciden en renunciar a su derecho natural sobre todas las cosas y aceptan ser gobernados por un tercero que no es parte de dicho pacto $^{30}$.

\footnotetext{
${ }^{29}$ MARCOS, Dolores, “Acerca de los Conceptos de Política y Soberanía en Carl Schmitt y Thomas Hobbes”, Foro Interno, no 4, 2004, p. 52.

${ }^{30}$ BOBBIO, Norberto, Thomas Hobbes, 2ª ed, Fondo de Cultura Económica, México D.F., 1995, p. 51. vol.08, nº. 01, Rio de Janeiro, 2015. pp. 279-298 
Tanto para Bodin como para Hobbes la soberanía es entendida como la capacidad de mandar y decidir, pero Hobbes profundiza en la comprensión de las raíces de su legitimidad, localizándola en un contrato entre los hombres "cuya naturaleza violenta e incontrolable requiere de un poder que les asegure protección y seguridad a sus vidas y propiedades", puesto que la vida en el estado natural es "solitaria, pobre,

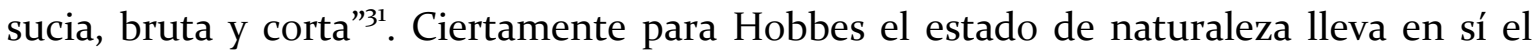
deseo de vivir, el miedo a la muerte, el egoísmo. En efecto, si :

Para un hombre no es absurdo, ni reprensible, ni contrario a los dictados de la recta razón usar toda su potencia para preservar y defender su cuerpo y los miembros que lo componen de la muerte y del dolor. Lo que no es contrario a la recta razón, es justo y a derechas. Por la voz derecho no se designa otra cosa que la libertad con que todo hombre tiene que hacer uso de sus facultades naturales de acuerdo con su recta razón. Por tanto, la base fundamental del derecho natural es que todo hombre, tan ampliamente como pueda, intente proteger su vida y sus miembros"32.

Así las cosas, se hace necesario para evitar éste que es realmente un estado de guerra, que los hombres cedan todo su poder y su fuerza a un solo hombre capaz de reducir todas las voluntades a una única voluntad. En consecuencia, tenía que existir una autoridad suprema que hiciera cumplir la ley y solventara los conflictos, que diera efectividad a las instituciones del Estado.

Para Leo Strauss, a pesar de que la filosofía de Hobbes da cuenta de una explicación científica, su sistema se apoya en una nueva moralidad: "no es la oposición naturalista entre el apetito animal moralmente indiferente (o el afán de poder humano moralmente indiferente), por un lado, y el afán de conservación moralmente indiferente, por el otro, sino la oposición moral y humanista entre la vanidad

\footnotetext{
${ }^{31}$ YORIS VILLASANA, Corina, "Soberanía: Aproximación Histórica a un Concepto Medieval", en PÉREZ TORIBIO, Juan Carlos y STRAKA, Tomás (comp.), El Problema de la Soberanía: Su Historia ante el S. XXI, Universidad Católica Andrés Bello, Caracas, 2007, p. 15.

${ }^{32}$ GÓMEZ ARBOLEYA, Enrique, Historia de la Estructura..., op. cit., supra 16, p. 140. Véanse, sobre el pensamiento de Hobbes, DE JUAN LÓPEZ, Sabino, Thomas Hobbes o la Unidad de Naturaleza y Sociedad, Erasmus Ediciones, Barcelona, 2009; RODRÍGUEZ FEO, Joaquín, Thomas Hobbes. Tratado sobre el Ciudadano, UNED, Madrid, 2009; y BOBBIO, Norberto, Estudios de Historia de la Filosofía: de Hobbes a Gramsci, Debate, Madrid, 1985, especialmente el capítulo dedicado a "El Modelo Iusnaturalista", pp. 73 y ss.
} 
fundamentalmente injusta y el miedo a una muerte violenta fundamentalmente justo lo que constituye el fundamento de la filosofía política de Hobbes"33.

Hobbes trata de deducir el derecho natural, la ley natural y la virtud a partir del principio de la autoconservación, que describe de forma negativa, como "evitando la muerte" y no como "conservando la vida". Para Hobbes no existe un summum bonum pero sí hay un summum malum, la muerte. De este modo se plantea el miedo a la muerte violenta como raíz de todo derecho y principio de toda moralidad. Si el Estado tiene origen en el miedo recíproco, su creación, según Strauss, tiene una justificación moral y no meramente técnica ${ }^{34}$. Para Strauss, las contradicciones de la obra de Hobbes son el producto de la asunción del método de la ciencia. Si se eliminara el velo cientificista y se asumiera el postulado moral, esas contradicciones podrían ser explicadas:

Según Hobbes, los derechos que integran la soberanía que son derechos naturales de una clase determinada- se derivan de las leyes de la naturaleza, y las leyes de la naturaleza, a su vez, se derivan del derecho de la naturaleza: sin el derecho de la naturaleza no existiría el derecho de soberanía. El derecho de la naturaleza, al ser el derecho de cada individuo, es anterior a la sociedad civil, y predetermina sus fines. Aún más, el derecho fundamental de la naturaleza se mantiene vivo dentro de la sociedad, en tanto en cuanto que mientras el derecho del soberano puede ser desconocido el derecho de la naturaleza no puede ser desconocido ${ }^{35}$.

Siguiendo a Strauss, la parte del derecho de naturaleza que conservan los hombres dentro del Estado es tal que implica la posibilidad de realizar una demanda subjetiva de derechos frente al soberano. La consecuencia de esto no es otra que abrir el camino a la teoría de los derechos naturales en el sentido del liberalismo moderno.

El absolutismo establece que el soberano actúa políticamente para garantizar la seguridad y la libertad de los asociados mediante las leyes civiles y éstos en correspondencia deben obedecer. El liberalismo quiere garantizar un ámbito de acción contra las intervenciones del Estado a través de la protección de las libertades negativas de los ciudadanos. Podría, por tanto, afirmarse que absolutismo político y un cierto tipo

\footnotetext{
33 STRAUSS, Leo, La filosofía política de Hobbes. Su Fundamento y su Génesis, Fondo de Cultura Económica, México, 2006, p. 54.

${ }^{34}$ Ibid., p. 48.

${ }^{35}$ STRAUSS, Leo, Qué es Filosofía Política, Guadarrama, Madrid, 1970, p. 260.
} vol.08, $n^{\circ}$. 01, Rio de Janeiro, 2015. pp. 279-298 
de liberalismo coexisten en Hobbes y se reclaman mutuamente; el primero para obligar a los hombres, mediante el temor y la amenaza coactiva a respetar los pactos, las leyes civiles y naturales; el segundo porque, una vez limitadas las pasiones naturales, es justo hacer posible el despliegue de la libertad. Este despliegue es concebido por Hobbes en términos de protección de unas libertades negativas que permiten salvaguardar la propiedad y el tráfico económico de los individuos contra las intervenciones de un poder político ejercido por el soberano. De este modo, podemos concluir que el Estado en Hobbes no surge del consentimiento de las personas a él sujetas, sino de una transferencia de poder. Al ceder el individuo su poder a un soberano por temor a la muerte, acepta perder sus derechos políticos para así asegurar la esfera de los intereses privados. El concepto de poder político que se deduce no está referido a una experiencia política sino a una experiencia privada determinada por la necesidad de asegurar la esfera de los intereses privados. Con esto se señala que en la lógica de la representación política de Hobbes se encuentra la raíz de la desaparición de la actuación política de los ciudadanos ${ }^{36}$.

La conexión instrumental entre el Estado soberano y la protección del individuo - "el bien del pueblo y el bien del soberano nunca discrepan"37 -, hacen que el mantenimiento y la defensa individual de la soberanía del Estado descansen precisamente en el provecho y la protección de los propios individuos. Tal y como se expresa en el Leviathan los mandatos del soberano se encuentran sometidos a la criba de una racionalidad puramente instrumental y utilitaria que los circunscribe a los bienes necesarios para la paz, en su propio país, y para la ayuda recíproca contra los enemigos, en el extranjero ${ }^{38}$. En la concepción de Hobbes uno de los modos en que se manifiesta la soberanía absoluta es en el derecho que asiste al soberano sobre la vida y la muerte de los súbditos, tanto en los castigos que puede aplicar, como en la posibilidad de declarar la guerra ${ }^{39}$.

${ }^{36}$ CORTÉS RODAS, Francisco, "El Contrato Social en Hobbes ¿Absolutista o Liberal?", Estudios Políticos, no 37, julio-diciembre 2010, p. 31.

${ }^{37}$ HOBBES, Thomas, Del Leviatán o la Materia, Forma y Poder de un Estado Eclesiástico y Civil, Fondo de Cultura Económica, México, 2006, p. 285.

${ }^{38}$ Ibid., p. 177. Véanse capítulos XVII-XVIII.

${ }^{39}$ MARCOS, Dolores, Acerca de los Conceptos..., op. cit., supra 25, p. 53. 
Pese a todo, aquí se encuentra el verdadero nudo gordiano de la construcción hobbesiana del concepto de soberanía, un extremo que atraviesa, por cierto, todo el devenir histórico del concepto. Si el sometimiento a los requerimientos de la soberanía del Estado tiene como límite infranqueable la vida, los derechos y la protección del individuo, ¿qué tratamiento y consideración merecen los atentados del Estado contra los individuos? Hace ya algunos años que Hans Welzel sintetizó magistralmente la objeción: "que el Estado obra siempre justamente frente a sus súbditos por virtud del contrato originario, y que, sin embargo, es posible que surja, de nuevo, un estado de naturaleza entre el Estado y los ciudadanos, es una contradicción insuperable dentro del sistema de Hobbes"40.

Las tesis de Hobbes disgustaron tanto a los partidarios del monarca como a los del Parlamento: a los primeros por su racionalismo individualista y protodemocrático; a los segundos, porque desembocaban en la defensa del absolutismo monárquico, aunque en realidad esta conclusión no era más que circunstancial y no afectaba al núcleo de su razonamiento: la articulación de un poder público soberano capaz de representar a toda la sociedad ${ }^{41}$.

\section{LA TEORÍA POLÍTICA DE JOHN LOCKE}

John Locke elaborará respuestas, un siglo más tarde, a las posturas absolutistas de Hobbes y los monárquicos. Para Locke es necesario garantizar la seguridad de la propiedad de los individuos (vida, libertad y bienes) por la inseguridad existente en el estado de naturaleza. Locke parte de un estado de naturaleza que no es un estado de guerra sino más bien una condición en la que los derechos individuales están garantizados de manera imperfecta. Para obtener las adecuadas garantías se ha de establecer una sociedad civil o política y posteriormente un gobierno y, con este fin, cada hombre cede a la comunidad sus derechos, en tanto necesario para el bien común, y no más allá ${ }^{42}$.

\footnotetext{
${ }^{40}$ WELZEL, Hans, Introducción a la Filosofía del Derecho, Aguilar, Madrid, 1971, pp. 125-126.

${ }^{41}$ VARELA SUANZES, Joaquín, “La Soberanía en la Doctrina Británica”, Fundamentos. Cuadernos monográficos de Teoría del Estado, Derecho Público e Historia Constitucional, no 1, 1998, p. 98.

${ }^{42}$ MERRIAM JR.., Charles Edward, History of the Theory..., op. cit., supra 10, p. 16.
} vol.08, $n^{\circ}$. 01, Rio de Janeiro, 2015. pp. 279-298 
La legitimación y la autoridad del Estado surgen, precisamente, por la superación de la inseguridad hobbesiana y la protección de los bienes lockeana. Se crea la sociedad civil y política a través de un contrato, y se crea al gobierno como agente de esa sociedad. La sociedad está subordinada al individuo, y el gobierno a la sociedad. La disolución del gobierno no implica la liquidación de la sociedad ${ }^{43}$. La tradición contractualista ha sostenido que se precisan dos contratos sucesivos para dar origen al Estado: el primero es el 'pacto de sociedad', por el cual un grupo de hombres decide vivir en comunidad, y el segundo es el 'pacto de sujeción', en el cual estos hombres se someten a un poder común.

En Locke el pueblo, que tiene el verdadero poder soberano, otorga a los poderes su confianza sin someterse a ellos, justificando la rebelión en el caso de que la autoridad no cumpla con sus objetivos. Resulta claro que "cuando un hombre entra en la sociedad civil y se convierte en miembro de una república, renuncia al poder que tenía para castigar los delitos contra la ley de la naturaleza”, éste es el origen de los poderes legislativo y ejecutivo. Locke entiende que, tras el pacto social, los individuos seguían conservando sus "derechos naturales", al residir en el conjunto de ellos la soberanía. El Estado que resulta del pacto, cuyo órgano supremo era el poder legislativo, tenía la principal finalidad de proteger esos "derechos naturales" a la propiedad, la vida y la seguridad $^{44}$. Los poderes originarios del hombre en el estado de naturaleza se transforman, gracias al contrato, en los poderes políticos de la sociedad civil, que, a diferencia de lo que sucede en el caso de Hobbes, son limitados.

Pero además de los límites a los que están sujetos los poderes del Estado, para Locke, por encima de éstos estaba el poder soberano del pueblo y sostuvo que la violación de los límites del poder legislativo justificaba el derecho de resistencia del

\footnotetext{
${ }^{43}$ VÁRNAGY, Tomás, "El Pensamiento Político de John Locke y el Surgimiento del Liberalismo", en BORON, Atilio A., (ed.), La Filosofia Política moderna. De Hobbes a Marx, CLACSO, Buenos Aires, 20oo, p. 6o. Véase asimismo LOCKE, John, Ensayo sobre el Gobierno Civil, Editorial Porrúa, Méjico, 2003, Segundo Ensayo sobre el Gobierno Civil, Losada, Buenos Aires, 2003, y Carta sobre la Tolerancia, (6a ed.), Tecnos, Madrid, 2008. Sobre el pensamiento de Locke, véase, por ejemplo, LASALLE RUIZ, Jose María, John Locke y los Fundamentos Modernos de la Propiedad, Dykinson, Madrid, 2001; SPELLMAN, William M., John Locke, Palgrave Macmillan, 1997; y DUNN, John, The Political Thought of John Locke, Cambridge University Press, 1988.

${ }^{44}$ VARELA SUANZES, Joaquín, "La Soberanía en la Doctrina Británica (de Bracton a Dicey)", Fundamentos. Cuadernos monográficos de Teoría del Estado, Derecho Público e Historia Constitucional, no 1. Oviedo, 1998, p. 98. Documento disponible en http://www.unioviedo.es/constitucional/fundamentos/primero/pdf/varela.pdf 
pueblo $^{45}$. El comportamiento tiránico disuelve la autoridad legítima y restaura la libertad natural y la igualdad que existe en el estado de naturaleza. Así, si un padre trata de asesinar a sus hijos, éstos tienen derecho a defenderse. Un gobernante que no deja recursos abiertos a sus súbditos, víctimas de injusticias, los obliga a considerarlo como injusto y con derecho a castigar su opresión. Es el gobernante el que crea el estado de guerra cuando incurre en cierto tipo de arbitrariedades.

El deseo de eliminar el riesgo del despotismo lleva a Locke a reconocer el poder soberano que tiene el pueblo de destituir o cambiar al poder legislativo si considera que se aparta de las finalidades para las que fue instituido:

A pesar de que en una comunidad política sólida y bien constituida, que actúa de acuerdo con su propia naturaleza, es decir, para la salvaguardia de la comunidad, no puede existir sino un poder supremo único, el legislativo, al que todos los demás se encuentran y deben estar subordinados, como tal poder legislativo es únicamente un poder al que se ha dado el encargo de obrar para la consecución de determinadas finalidades, le queda siempre al pueblo el poder supremo de apartar o cambiar los legisladores, si considera que actúan de una manera contraria a la misión que se les ha encomendado (...). De este modo, la comunidad conserva perpetuamente el poder supremo de sustraerse a las tentativas $y$ maquinaciones de cualquier persona ${ }^{46}$.

Los textos de Locke contienen un discurso político potencialmente revolucionario, ya que frente al abuso del poder del Estado el pueblo conserva el derecho a la rebelión, que se ejercerá sólo en casos extremos. Su justificación de la insurrección cuando el gobierno se vuelve tiránico y rompe el contrato es considerada como uno de los elementos democráticos de su teoría política y una idea explosiva y subversiva para la época. Para Locke quienes usan la fuerza contra la ley, actúan como verdaderos rebeldes, y concluye que la rebelión no está dirigida contra las personas, sino contra la autoridad, y "aquellos que las quebrantan (la constitución y las leyes) y justifican por la fuerza esa violación (...) son los verdaderos rebeldes en sentido estricto" 47 .

El pueblo es quien decide cuándo se ha roto la confianza y tiene este poder porque subsiste como comunidad pese a la disolución del gobierno, y cualquiera que

\footnotetext{
${ }^{45}$ Ibid., p. 103.

${ }^{46}$ LOCKE, John, Ensayo sobre el Gobierno Civil, op. cit., supra 39, cap. XIII, parr. 149.

${ }^{47}$ Véase VÁRNAGY, Tomás, El Pensamiento Político..., op. cit., supra 32, p. 65.
} 
sea la razón de la ruptura, "el poder revierte de nuevo en la sociedad, y el pueblo tiene derecho a actuar en calidad de poder supremo y constituirse ellos mismos en legislativo". Como se ha dicho ya, la disolución del gobierno no implica la disolución de la sociedad: a diferencia de Hobbes, el peligro de la anarquía no puede ser invocado para tolerar el despotismo ${ }^{48}$.

El principal temor de Locke se encuentra en el abuso de poder y, por tanto, su esfuerzo se centra en establecer límites a su ejercicio. Uno de los límites más relevantes que establece Locke es la inviolabilidad de la propiedad de los particulares, el derecho de propiedad es un derecho irrenunciable. Sin embargo, la finalidad de las limitaciones al poder político no es la garantía de la vida, la libertad y la propiedad de todos los individuos que conforman el Estado, se trata de proteger a los propietarios. Locke no era un republicano en sentido estricto, sino un parlamentarista monárquico, en favor de un gobierno burgués asociado a la aristocracia. Existen, de acuerdo a C. B. Macpherson, dos premisas fundamentales en el pensamiento de Locke, la primera es que los trabajadores no son miembros con pleno derecho del cuerpo político, y la segunda es que no viven ni pueden vivir una vida plenamente racional. Tal vez pertenezcan ambas a la Inglaterra de su época, que consideraba natural la incapacidad política de los trabajadores. Los pobres están en la sociedad civil, pero no son miembros plenos de ella ni son considerados como ciudadanos. Si bien el derecho a la rebelión pertenece a la mayoría, se trata de una mayoría capaz de decisiones racionales; por lo tanto, los trabajadores estaban excluidos por ser incapaces de una acción política racional ${ }^{49}$.

John Locke se constituye como el referente por excelencia del liberalismo, entendido como un modelo que tiende a la limitación del poder político. A partir de este dato, el contractualismo es usado para crear, por una parte, una comunidad política en la que la posición de los propietarios queda investida de legitimidad y, por otra, para el establecimiento de un gobierno lo bastante abstencionista como para que no interfiera en la propiedad privada o en las relaciones comerciales de los particulares, pero lo suficientemente fuerte como para hacer respetar el derecho de los propietarios. Casi un siglo después, Rousseau calificaría el contrato en Locke como "de carácter

\footnotetext{
${ }^{48}$ Ibid, p. 64.

49 MACPHERSON, Crawford Brough, La Teoría Política del Individualismo Posesivo: De Hobbes A Locke, Barcelona, Península, 1974, pp. 191-196.
} 
fraudulento" en su Discurso sobre el origen de la desigualdad de los hombres, a pesar de esto, o tal vez precisamente por esto, en éste se encuentran los fundamentos políticos y económicos del liberalismo ${ }^{50}$.

\section{J.J. ROUSSEAU Y LA SOBERANÍA COMO EJERCICIO DE LA VOLUNTAD GENERAL}

Será J. J. Rousseau, ya llegado el siglo XVIII, el que acabará cerrando el itinerario moderno del concepto de soberanía. Partiendo del principio de que la simple fuerza no genera derecho y de que únicamente de la legitimidad puede hacer nacer la obligación de obediencia, Rousseau se adentra en el ambicioso plan de fundamentar y legitimar el orden social, "un derecho sagrado que sirve de base a todos los demás"51. En El Contrato Social, la recuperación roussoniana del viejo modelo contractualista incorpora, sin embargo, una perspectiva radicalmente nueva: "antes de examinar el acto por el cual un pueblo elige un rey, seria conveniente examinar el acto por el cual un pueblo es pueblo".

Un pueblo lo es, pues, por virtud de un contrato. Un contrato con fuerza bastante para proteger la persona y los bienes de los contratantes, sin hipotecar su libertad; un contrato que incluye la enajenación total de los bienes y derechos de los asociados a toda la comunidad; un contrato en el que se gana el equivalente de todo lo que se pierde. Un contrato en el que, en esencia, "cada uno de nosotros pone en común su persona y todo su poder bajo la suprema dirección de la voluntad general; y cada miembro es considerado como parte indivisible del todo", convirtiendo "al instante la persona particular de cada contratante en un cuerpo moral y colectivo" ${ }^{22}$.

Así es como aparece un nuevo sujeto político, un cuerpo moral, colectivo y unitario, con voluntad propia y diferente de las voluntades particulares. La voluntad

\footnotetext{
${ }^{50}$ RAMÍREZ ECHEVERRI, Juan David, Thomas Hobbes y el Estado Absoluto: Del Estado de Razón al Estado de Terror, Universidad de Antioquia, 2010, p. 22. Disponible en http://www.udea.edu.co/portal/page/portal/bibliotecaSedesDependencias/unidadesAcademicas/Fac ultadDerechoCienciasPoliticas/BilbiotecaDiseno/Archivos/Tab1o/o2\%2oThomas_Hobbes_Juan\%2oR am\% $3 \%$ ADrez.PDF.

${ }^{51}$ ROUSSEAU, Jean Jacques, Contrato social, Austral, Madrid, 2007 (12aㅡ ed.), p. 36. Sobre Rousseau véanse, por ejemplo, STAROBINSKI, Jean, Jean-Jacques Rousseau: la transparencia y el obstáculo, Madrid, Taurus, 1983 y POLIN, Raymond, La Politique de la Solitude: Essai sur la Philosophie Politique de Jean-Jacques Rousseau, Sirey, Paris, 1971.

${ }^{52}$ Ibid., p. 46.
} 
general es la nueva expresión de la soberanía y, para Rousseau, el nuevo soberano. Rousseau quiere modificar al mismo tiempo el problema del contrato social y las respuestas que tradicionalmente se le ha dado. El problema consiste en volver a la primera institución: la del pueblo. El pueblo pasa a estar ahora en el centro de la operación contractual, mientras que previamente, ésta tenía por función destituirlo y arrebatarle toda posibilidad de ser el sujeto efectivo de la soberanía ${ }^{53}$.

La soberanía, para Rousseau, no es otra cosa que la activación y el ejercicio de la voluntad general, indelegable e intransmisible, puesto que "el soberano sólo puede estar representado por sí mismo"54. Tampoco la soberanía es divisible, porque la voluntad o es general o no lo es, o es de todo el pueblo o es de una parte del mismo. Dura crítica de Rousseau al pensamiento de quienes "después de haber despedazado el cuerpo social, por un prestigio digno de la magia, unen sus piezas no se sabe cómo" 55 . No es fácil huir del carácter absoluto de una soberanía que puede obligar a los ciudadanos a ser libres y que, supuesto que ha de ordenar las partes (individuos) de la manera más conveniente al todo (interés común), ha de contar con "una fuerza universal y compulsiva que mueva y disponga cada parte de la manera más conveniente para el todo" ${ }^{56}$.

El organicismo roussoniano, de indudable impronta en el concepto de soberanía, aparece con palmaria evidencia cuando afirma que, al igual que la naturaleza ha dado a los humanos un poder absoluto sobre todos los miembros de su cuerpo, "también el pacto social otorga al cuerpo político un poder absoluto sobre todo lo suyo", añadiendo que "este mismo poder, dirigido por la voluntad general, es el que lleva el nombre de soberanía" ${ }^{27}$. Cuando se busca la esencia del acto de soberanía, Rousseau no deja espacio a la ambigüedad y marca inequívocamente las distancias con el pensamiento soberanista que le precede: "no es una convención del superior con el inferior, sino una convención -legítima, equitativa, útil y sólida- del cuerpo con cada uno de sus miembros" ${ }^{28}$.

\footnotetext{
53 ZARKA, Yves Charles, "Rousseau y la Soberanía del Pueblo", Derechos y Libertades, no 15, junio de 2006, p. 54, disponible en http://e-archivo.uc3m.es/bitstream/handle/10016/6992/DyL-2006-15Zarka.pdf?sequence $=1$.

${ }^{54}$ ROUSSEAU, Jean Jacques, Contrato social, op. cit., supra 35, p. 55.

${ }^{55}$ Ibid., p. 57.

${ }^{56}$ Ibid., p. 60.

${ }^{57}$ Ibídem.

${ }^{58}$ Ibid., p. 62.
} 
Para Rousseau, prácticamente carece de sentido la pregunta sobre el alcance de los derechos del soberano en relación a los de los ciudadanos, puesto que equivaldría a preguntar "hasta qué punto pueden estos obligarse consigo mismos, cada uno de ellos respecto a todos, y todos respecto a cada uno de ellos"59. De esta manera, el acto asociativo va a dar lugar a una doble vía obligacional entre individuo y soberano, de manera que "cada individuo, contratando por decirlo así consigo mismo, está obligado bajo dos aspectos, a saber, como miembro del soberano respecto a los particulares, y como miembro del Estado respecto al soberano ${ }^{60}$.

No aparecen, en cambio, con idéntica nitidez las obligaciones del soberano que, compuesto por individuos particulares,

No hay ni puede haber interés contrario al suyo; Por consiguiente, el poder soberano no tiene ninguna necesidad de garantía con respecto a los súbditos, porque es imposible que el cuerpo quiera perjudicar a todos sus miembros (...). El soberano, sólo por ser lo que es, es siempre todo lo que debe $\operatorname{ser}^{61}$.

Puede verse en estas palabras la superación del lenguaje de la moral y de la metafísica por el de la teología: el ser que es siempre lo que debe ser es tradicionalmente el ser divino. Así la voluntad general es indestructible, no puede ser ni aniquilada, ni corrompida. Tanto es así que numerosos autores apuntan a que sus artículos de fe son propiamente teológicos: "la existencia de la divinidad, la vida venidera, la felicidad de los justos y el castigo de los malos" y otros son de carácter teológico-político: "la santidad del contrato". Se encuentra así realizada la sacralización de lo secular en la doctrina de la soberanía del pueblo ${ }^{62}$.

El poder soberano no es, pese a todo, conceptualmente ilimitado, debiendo distinguirse cuidadosamente entre los derechos de los ciudadanos y los del soberano, "los deberes que tienen que llenar los primeros en calidad de súbditos del derecho natural, cualidad de que deben gozar por el hecho de ser hombres" ${ }^{\text {"3 }}$. El (soberano no actúa sobre los intereses y la voluntad particular mientras no esté en cuestión el interés común y no se encuentre comprometida la voluntad general. Así pues, el pacto

\footnotetext{
${ }^{59}$ Ibídem.

${ }^{60}$ Ibid., p. 47.

${ }^{61}$ Ibid., pp. 48 y 49 .

${ }^{62}$ ZARKA, Yves Charles, Rousseau y la Soberanía..., op. cit., supra 37, pp. 58-61.

${ }^{63}$ Ibid., p. 60.
} 
roussoniano únicamente incluye la enajenación de la parte de poder, bienes y libertad que interesan e importan a la comunidad social, si bien, y la cuestión no es en modo alguno menor, "mas es preciso convenir también que sólo el soberano es juez para apreciarlo" ${ }^{64}$. Porque es evidente que "de aquí se deduce que el poder soberano, por muy absoluto, sagrado e inviolable que sea, no excede, ni puede exceder de los límites de las convenciones generales, y que todo hombre puede disponer plenamente de lo que por virtud de esas convenciones le han dejado de sus bienes y de su libertad"65. Son conocidas y reconocidas la complejidad, polivalencia y versatilidad que acompañan el pensamiento de Rousseau, pero, entre ellas, esta evidencia roussoniana es, quizá una del zonas más oscuras de su pensamiento, que, por razones de enfoque, no nos toca esclarecer aquí y ahora.

Rousseau ha descubierto el concepto de voluntad general, ha redescubierto el concepto de comunidad y ha reformulado el principio de la soberanía. El ambicioso intento roussoniano de conciliar legitimidad y seguridad, derecho e interés, justicia y utilidad, conducen a una teoría política cercana a la idealización y carente, en no poca medida, de una suficiente institucionalización. Como señalara en su momento Habermas, Rousseau mezcla la introducción de un nuevo principio de legitimación política con propuestas de institucionalización de una dominación justa ${ }^{66}$.

\section{CONCLUSIONES}

Acudiendo a un razonamiento de trazo grueso, susceptible por tanto de numerosas e importantes matizaciones, cabría decir que el racionalismo disociado de la teología y el individualismo liberado de la tutela de la religión van a posibilitar, en última instancia, la transformación y el desplazamiento de los viejos centros de poder sobre los que se asentaban las monarquías medievales hasta un nuevo modelo de Estado.

Con el nacimiento del mundo moderno el espacio de la política es conceptualizado y encarado, ante todo, como una construcción humana, nacida de la racionalidad humana y apta para unas relaciones sociales que han de desplegarse en el

\footnotetext{
${ }^{64}$ Ibídem.

${ }^{65}$ Ibid., p. 62.

${ }^{66}$ HABERMAS, Jürgen, “La Legitimidad Hoy”, Revista de Occidente, no 9, p. 6. 
ámbito de lo humano, con su propia ratio, distinta de la ratio theologica. Por eso cambia incluso su denominación, apareciendo en Maquiavelo la designación de lo stato, que describía hasta entonces la situación cambiante e instantánea de una persona o entidad. Lo stato sustituye a la clásica res publica y este cambio en los términos subraya una realidad nueva: la vida política se hace móvil, ahora es un mundo cambiante creado por humanos.

A partir de la concepción del contrato social, tomado como fundamento, Thomas Hobbes establecerá los cimientos del absolutismo. Los seres humanos, en su estado de naturaleza, viven en una lucha permanente y continua. Los individuos, para Hobbes, con el objetivo de conseguir la paz y la preservación de sí mismos, han creado un hombre artificial llamado Estado (suma de todos los poderes individuales) y han creado también las leyes que han sido establecidas por pactos entre ellos. La construcción hobbesiana del concepto de soberanía se ensombrece ante la falta de respuesta a una pregunta fundamental: $\mathrm{Si}$ el sometimiento a los requerimientos de la soberanía del Estado tiene como límite infranqueable la vida, los derechos y la protección del individuo, ¿qué tratamiento y consideración merecen los atentados del Estado contra los individuos?

John Locke dará respuesta a las posturas absolutistas de Hobbes. Para Locke es necesario garantizar la seguridad de la propiedad de los individuos (vida, libertad y bienes) por la inseguridad existente en el estado de naturaleza. La legitimación y la autoridad del Estado surgen, precisamente, por la superación de la inseguridad hobbesiana y la protección de los bienes lockeana. Se crea la sociedad civil y política a través de un contrato, y se crea al gobierno como agente de esa sociedad.

Las teorías de Locke contienen un discurso político potencialmente revolucionario, ya que frente al abuso del poder del Estado el pueblo conserva el derecho a la rebelión, que se ejercerá sólo en casos extremos. Su justificación de la insurrección cuando el gobierno se vuelve tiránico y rompe el contrato es considerada como uno de los elementos democráticos de su teoría política y una idea explosiva y subversiva para la época. El principal temor de Locke se encuentra en el abuso de poder y, por tanto, su esfuerzo se centra en establecer límites a su ejercicio. Uno de los límites más relevantes que establece Locke es la inviolabilidad de la propiedad de los particulares, el derecho de propiedad es un derecho irrenunciable. Sin embargo, la 
finalidad de las limitaciones al poder político no es la garantía de la vida, la libertad y la propiedad de todos los individuos que conforman el Estado, se trata de proteger a los propietarios.

Será J. J. Rousseau, ya en el siglo XVIII, el que acabará cerrando el itinerario moderno del concepto de soberanía. Partiendo del principio de que la simple fuerza no genera derecho y de que únicamente de la legitimidad puede hacer nacer la obligación de obediencia, Rousseau se adentra en el ambicioso plan de fundamentar y legitimar el orden social, un derecho sagrado que sirve de base a todos los demás.

Un pueblo lo es, para Rousseau, por virtud de un contrato. Un contrato con fuerza bastante para proteger la persona y los bienes de los contratantes, sin hipotecar su libertad; un contrato que incluye la enajenación total de los bienes y derechos de los asociados a toda la comunidad; un contrato en el que se gana el equivalente de todo lo que se pierde. Así es como aparece un nuevo sujeto político, un cuerpo moral, colectivo y unitario, con voluntad propia y diferente de las voluntades particulares. La voluntad general es la nueva expresión de la soberanía y, para Rousseau, el nuevo soberano.

Este breve recorrido histórico a través del concepto de soberanía no autoriza ninguna invocación extemporánea del mismo, ni mucho menos, ninguna operación de dislocación teórica de sus contenidos definitorios, pero sí nos permite localizar y calibrar adecuadamente la evolución y complejidad de un elemento clave para entender la verdadera dimensión y funcionalidad del Estado moderno. La conceptualización de la soberanía es indisociable del problema de la legitimación política, y, como acertadamente señalara Marramao, "el aspecto de la legitimidad como correlato imprescindible de la noción de soberanía señala la presencia de una constitutiva, fisiológica ambivalencia entre fuerza y consenso, efectividad y legalidad, decisión y norma, que hace inútil (o irremisiblemente unilateral) todo intento de resolver los problemas conectados con la traducción moderna de la 'summa legibusque soluta potestas' reconduciéndolos a uno o a otro de los dos polos"67.

\section{STATE SOVEREIGNTY IN A HISTORICAL CONTEXT. NOTES ON HOBBES, LOCKE AND ROUSSEAU}

\footnotetext{
${ }^{67}$ MARRAMAO, Giacomo, Soberanía..., op. cit., supra 7, p. 39.
} 


\begin{abstract}
It's our primary idea the existence of a necessity for placing legal-political concepts in their historical contexts given that no matter how they evolve and change in time, they are always, to a greater or lesser extent, debtors of the historic moment of their genesis. This study is intended to highlight some of the most relevant historical backgrounds in an approach to the concept of sovereignty. Sovereignty has a history, a tradition, and knowing about the past may allow us to envision new limitations, corrections and interpretations in its legal analysis. This brief history of the concept of sovereignty is meant to go deep in what once was the meaning of its adoption as a fundamental assumption of the existence of the state, and not so much of the government. Its importance lies in the fact that behind the principles and paradigms of sovereignty, there is a reality of tensions affecting the legal and political processes which origin must be indispensably understood.
\end{abstract}

Keywords: Sovereignty, modern State, Hobbes, Locke, Rousseau.

\title{
REFERENCIAS BIBLIOGRÁFICAS
}

BLAIR, Ann, The theater of nature: Jean Bodin and Renaissance science, Princeton University Press, 1997.

BOBBIO, Norberto, Estudios de Historia de la Filosofía: de Hobbes a Gramsci, Debate, Madrid, 1985.

BOBBIO, Norberto, Thomas Hobbes, $2^{\underline{a}}$ ed, Fondo de Cultura Económica, México D.F., 1995.

BODIN, Jean, Los Seis Libros de la República, Tecnos, (4ª ed.), Madrid, 2006.

CARRILLO SALCEDO, Juan Antonio, Soberanía del Estado y Derecho Internacional, Tecnos, Madrid, 1976

COHEN, Sami, "Les États et les "nouveaux acteurs"”, Politique internationale, $\mathrm{n}^{\circ}$ 107, primavera 2005.

CORTÉS RODAS, Francisco, "El Contrato Social en Hobbes ¿Absolutista o Liberal?", Estudios Políticos, no 37, julio-diciembre 2010.

DE JUAN LÓPEZ, Sabino, Thomas Hobbes o la Unidad de Naturaleza y Sociedad, Erasmus Ediciones, Barcelona, 2009.

DÍAZ, Elías, Sociología Filosofía del Derecho, Ed. Taurus, Madrid 1980. 
DUNN, John, The Political Thought of John Locke, Cambridge University Press, 1988.

FERRAJOLI, Luigi, "La crisis de la democracia en la Era de la Globalización”, Anales de la Cátedra Francisco Suárez, IVR 2005.

GARCÍA GESTOSO, Noemí, "Sobre los Orígenes Históricos y Teóricos del Concepto de Soberanía: Especial Referencia a los Seis Libros de la República de J. Bodino”, Revista de Estudios Políticos, no 120, abril-junio 2003.

GINER SANJULIÁN, Salvador, Historia del Pensamiento Social, (12ª ed.), Ariel, 2008.

GÓMEZ ARBOLEYA, Enrique, Historia de la Estructura y el Pensamiento social, Instituto de Estudios Políticos y Constitucionales, Madrid, 1976.

GONZÁLEZ VICÉN, Felipe, Estudios de Filosofía del Derecho, Universidad de La Laguna, 1979.

HILLGRUBER, Christian, "Soberanía-La Defensa de un Concepto Jurídico", InDret Revista para el Análisis del Derecho, Barcelona, vol. 1, 2009.

HOBBES, Thomas, Del Leviatán o la Materia, Forma y Poder de un Estado Eclesiástico y Civil, Fondo de Cultura Económica, México, 2006.

KENNEDY, David, "Sovereignty: Responding to Anghie and Aravamudan", Texas International Law Journal, vol. 3, verano 2006.

KOSKENNIEMI, Martti, "What Use for Sovereignty Today?", Asian Journal of International Law, vol. 1, 2011.

From Apology to Utopia. The Structure of International Legal Argument, Cambridge University Press, 2005.

LASALLE RUIZ, Jose María, John Locke y los Fundamentos Modernos de la Propiedad, Dykinson, Madrid, 2001.

LOCKE, John, Carta sobre la Tolerancia, (6ª ed.), Tecnos, Madrid, 2008.

Ensayo sobre el Gobierno Civil, Editorial Porrúa, Méjico, 2003.

Segundo Ensayo sobre el Gobierno Civil, Losada, Buenos Aires, 2003.

MACPHERSON, Crawford Brough, La Teoría Política del Individualismo Posesivo: De Hobbes A Locke, Barcelona, Península, 1974.

MAQUIAVELO, Nicolás, El Príncipe, M. E. Editores, Madrid, 1995.

MARCOS, Dolores, "Acerca de los Conceptos de Política y Soberanía en Carl Schmitt y Thomas Hobbes”, Foro Interno, № 4, 2004. 
MARRAMAO, Giacomo, "Soberanía: para una Historia Crítica del Concepto", Anales de la Cátedra Francisco Suárez, no 29, 1989.

MERRIAM JR., Charles Edward, History of the Theory of Sovereignty since Rousseau, Batoche Books, Kitchener, 2001.

MESNARD, Pierre, Jean Bodin en la Historia del Pensamiento, Instituto de Estudios Políticos, 1962.

Oeuvres philosophiques de Jean Bodin, Presses Universitaires de France, París, 1951.

NAGAN, Winston P. y HADDAD, Aitza M., "Sovereignty in Theory and Practice", San Diego International Law Journal, vol. 13, 2012.

POLIN, Raymond, La Politique de la Solitude: Essai sur la Philosophie Politique de JeanJacques Rousseau, Sirey, Paris, 1971.

RAMÍREZ ECHEVERRI, Juan David, Thomas Hobbes y el Estado Absoluto: Del Estado de Razón al Estado de Terror, Universidad de Antioquia, 2010.

RODRÍGUEZ FEO, Joaquín, Thomas Hobbes. Tratado sobre el Ciudadano, UNED, Madrid, 2009.

ROUSSEAU, Jean Jacques, Contrato social, Austral, Madrid, 2007 (12 $2^{\mathrm{a}}$ ed.).

SAAVEDRA LÓPEZ, Modesto, Doce Lecciones de Filosofía del Derecho, Universidad de Granada, 2011.

SCHULZE, Hagen, Estado y Nación en Europa, Grijalbo-Mondadori, Barcelona, 1996.

SENN, Marcel, "Sovereignty - Some critical Remarks on the Genealogy of Governance", Journal on European History of Law, vol. 1, no 2, 2010.

SPELLMAN, William M., John Locke, Palgrave Macmillan, 1997.

STAROBINSKI, Jean, Jean-Jacques Rousseau: la transparencia y el obstáculo, Madrid, Taurus, 1983.

STRAUSS, Leo, La filosofía política de Hobbes. Su Fundamento y su Génesis. Fondo de Cultura Económica, México, 2006.

Qué es Filosofía Política, Guadarrama, Madrid, 1970.

VARELA SUANZES, Joaquín, "La Soberanía en la Doctrina Británica”, Fundamentos. Cuadernos monográficos de Teoría del Estado, Derecho Público e Historia Constitucional, noำ 1998. 
VÁRNAGY, Tomás, "El Pensamiento Político de John Locke y el Surgimiento del Liberalismo", en BORON, Atilio A., (ed.), La Filosofía Política moderna. De Hobbes a Marx, CLACSO, Buenos Aires, 2000.

WELZEL, Hans, Introducción a la Filosofía del Derecho, Aguilar, Madrid, 1971.

YORIS VILLASANA, Corina, "Soberanía: Aproximación Histórica a un Concepto Medieval”, en PÉREZ TORIBIO, Juan Carlos y STRAKA, Tomás (comp.), El Problema de la Soberanía: Su Historia ante el S. XXI, Universidad Católica Andrés Bello, Caracas, 2007.

ZARKA, Yves Charles, "Rousseau y la Soberanía del Pueblo”, Derechos y Libertades, no 15, junio de 2006.

Trabalho enviado em 15 de setembro de 2014.

Aceito em 11 de fevereiro de 2015. 